\title{
Moonlight: a intertextualidade e o seu diálogo com a crítica genética na adaptação cinematográfica contemporânea
}

Moonlight: intertextuality and its dialogue with genetic criticism in the contemporary film adaptation

Luz de Luna: la intertextualidad y su diálogo con la crítica genética en la adaptación cinematográfica contemporánea

DOI: https://doi.org/10.1590/1809-58442021211

\section{Roberto Gustavo Reiniger Neto ${ }^{1}$}

http://orcid.org/0000-0002-0773-3667

${ }^{1}$ (Universidade Federal de São Carlos, Departamento de Artes e Comunicação. São Carlos - SP, Brasil).

\section{Resumo}

No universo da adaptação literária, a narrativa cinematográfica contemporânea cada vez mais ultrapassa a fronteira das relações entre as páginas de uma obra ficcional e as imagens de um filme. $\mathrm{O}$ cinema, tal qual o audiovisual que o cerca, constrói o seu discurso de modo convergente (JENKINS, 2006), buscando referenciais intertextuais e interdisciplinares (STAM, 2006). Neste processo outras formas de arte e escrita podem abrir as portas para uma linguagem experimental e independente, mas, esta estaria embasada de fato para uma investigação teórica e crítica? Na busca de uma resposta, ou ao menos um indício sobre esta questão, este estudo dialoga também com a crítica genética (SALLES, 2004), para analisar o filme Moonlight: Sob a luz do luar (Moonlight, 2016), adaptado da peça teatral In Moonlight Black Boys Look Blue (2003). Seu roteiro ao se distanciar do seu texto de origem, ressignifica o seu conteúdo, e desta forma, consegue construir a sua própria trama.

Palavras-chave: Adaptação. Cinema Contemporâneo. Intertextualidade. Crítica Genética. Moonlight.

\begin{abstract}
In the universe of literary adaptation, contemporary cinematic narrative increasingly crosses the boundary of relationships between the pages of a fictional work and the images of a film. The cinema, like the audiovisual that surrounds it, constructs its discourse in a convergence (JENKINS, 2006) way, seeking intertextual and interdisciplinary references (STAM, 2006). In this process other forms of art and writing may open the door to an experimental and independent language, but is this grounded in theoretical and critical inquiry? In search of an answer or at least a clue on this issue, this study also dialogues with genetic criticism (SALLES, 2004) to analyze the movie Moonlight (2016), adapted from the play In Moonlight Black Boys Look Blue (2003).
\end{abstract}


Its script, when distancing itself from its original text, re-signifies its content, and in this way, manages to build its plot.

Keywords: Adaptation. Contemporary Cinema. Intertextuality. Genetic Criticism. Moonlight.

\section{Resumen}

En el universo de la adaptación literaria, la narrativa cinematográfica contemporánea cruza cada vez más el límite de las relaciones entre las páginas de una obra de ficción y las imágenes de una película. El cine, como el audiovisual que lo rodea, construye su discurso de forma convergente (JENKINS, 2006) buscando referencias intertextuales e interdisciplinarias (STAM, 2006). En este proceso, otras formas de arte y escritura pueden abrir la puerta a un lenguaje experimental e independiente, pero ¿se basa esto realmente en una investigación teórica y crítica? En busca de una respuesta, o al menos una pista sobre esta pregunta, este estúdio también dialoga con la crítica genética (SALLES, 2004), para analizar la película Luz de Luna (Moonlight, 2016), adaptado de la obra teatral A la luz de la luna, los niños negros se ven azules (2003). Su guión, al distanciarse de su texto original, vuelve a significar su contenido y, por lo tanto, puede construir su propia trama.

Palabras clabe: Adaptación. Cine Contemporáneo. Intertextualidad. Crítica Genética. Luz de Luna.

Em fevereiro de 2017, o filme Moonlight: Sob a luz do luar (Moonlight, 2016) ganhou destaque na mídia pelos contratempos que enfrentou ao receber o Oscar de melhor filme. Fato inegável, sobretudo, pelas questões raciais da representatividade da sua equipe. Ocorre, porém, que tal filme é de tamanha riqueza que pode ainda ser explorado sobre outros vieses dentro da teoria do audiovisual. Essa produção será considerada como objeto deste estudo, não pelo fato ter sido produzida pela A24 Films; uma das mais recentes produtoras e distribuidoras independentes dos Estados Unidos, tampouco por inúmeros prêmios que tenha conquistado, desde sua fundação, em 2012. Moonlight requer certa atenção diante da teoria do audiovisual pelo fato da crítica, por vezes, não ter se atentado em explorar elementos da sua narrativa, definitivamente longe de qualquer padrão clássico, sobretudo, por seu roteiro ter sido adaptado da peça teatral In moonlight black boys look blue (2003), de Tarell Alvin McCraney.

$\mathrm{Na}$ atual conjuntura, aonde o audiovisual é visto como uma constante convergência de novas mídias e tecnologias, este estudo questiona: não haveria a possibilidade de se considerar essa interseção no que diz respeito também ao estudo do discurso do seu processo de criação? O estudo da história da adaptação aponta para a predominância de um binômio crítico-historiográfico já bem estruturado (REINIGER NETO, 2019), mas que, muitas vezes, não enxerga no intertexto da construção do seu conteúdo a oportunidade de contribuir com a crescente teoria do audiovisual contemporânea. À adaptação literária no cinema não cabe mais somente a fronteira traçada entre as páginas de uma obra ficcional e as imagens de um filme. Tão convergente quanto o próprio audiovisual em si, Moonlight nos serve como um 
exemplo de que a adaptação pode cada vez mais agregar as mais distintas formas de arte para a construção da sua narrativa.

Para embasar este recorte, em um primeiro momento, traz-se a obra de Robert Stam. Mesmo que suas principais publicações, como o artigo Teoria e prática da adaptação: Da fidelidade à intertextualidade (2006) e o livro A literatura através do cinema: Realismo, magia e a arte da adaptação (2008) trabalhem com um escopo quantitativo, mapeando o que o conteúdo cinematográfico processou e adaptou de discurso neste amplo espectro interdisciplinar. Segundo Stam (2006), agora não apenas os textos literários se enquadram nesta operacionalidade, mas também suas fontes sub ou para-literárias. Nesta comunhão, é no pós-estruturalismo; entre o dialogismo de Bakhtin e a intertextualidade de Kristeva, que este autor vê o cinema como mediador das artes na adaptação. Assim, não só a literatura e as artes plásticas, mas também o cinema e o audiovisual, carregam uma coletânea de obras, em algum nível, derivadas umas das outras.

Esta estratégia analítica tem como objetivo ir além do status quo crítico que lamenta o que foi perdido na transição entre um livro e um filme, reiterando uma suposta axiomática superior da literatura sobre o cinema. O pós-estruturalismo, supracitado, entra nesse embate na medida em que subverte esses preconceitos, sua semiótica trata todas as práticas de significação como um sistema de compartilhamento de sinais, ou uma interminável permutação de intertextualidades. Há de se considerar que a comunicação, dentro deste escopo, faz-se presente a partir do momento que um texto assim o faz, quando dorme com qualquer outro texto (DERRIDA apud. STAM, 2006). A obra de arte, independentemente da sua área, passa a ocupar a autarquia da comunhão; seu autor torna-se fissurado, fragmentado, um orquestrador de discursos preexistentes (STAM, 2006). Sua construção nada mais é do que híbrida, ou seja, mistura as suas próprias palavras com as palavras de outrem.

Nessa comunhão interdisciplinar e convergente - que em uma metáfora pode beirar os conceitos de Jenkins (2006) - a investigação de toda e qualquer forma de arte é válida, sobretudo, quando vem à tona a literalidade de fenômenos não-literais, e esta nova figura do autor consegue empregá-las na construção do seu novo discurso. O próprio termo 'adaptação' configura um melhor status, quando sobreposto à adaptação literária: não há mais lugares privilegiados para o romance, este, agora, convive com outras obras, as quais cada vez mais passarão por nova leituras e interpretações, somas e conjunções. Nem um texto, nem o seu autor, conseguem mais manter o papel de autoridade legal sobre as ramificações intertextuais (STAM, 2006) daquilo que produzem. Até porque outras formas podem ser criadas, ou atingidas, como o cinema, o qual diversos autores, como Deleuze, considera como um tradutor de pensamentos em termos audiovisuais: blocos de movimento em intervalos temporais (DELEUZE apud. STAM, 2006).

Mas como estudar, de fato, essa comunhão de discursos tão distintos? No resgate que Stam faz de autores do pós-estruturalismo, há o consenso da necessidade de uma maior liberdade nas interpretações das mais variadas adaptações, pois 
(...) como qualquer texto pode gerar uma infinidade de leituras, qualquer romance pode gerar um número infinito de leituras para a adaptação, que serão inevitavelmente parciais, pessoais, conjunturais, ou com interesses específicos (STAM, 2006, p. 27).

Com o objetivo de elencar quais e quantas produções podem estabelecer ligações com outras formas de arte, Stam consegue plenamente exemplificar seus apontamentos, seja no cinema clássico, ou contemporâneo; seja no início do pós-estruturalismo, no dialogismo de Bakhtin, ou na intertextualidade de Kristeva à Genette. Deste autor, cabe ressaltar a leitura que Stam faz deste conceito, em especial, quando trata da hipertextualidade - o momento em que um hipertexto transforma, modifica, elabora ou estende seu texto anterior, um hipotexto. No que tange ao cinema, suas adaptações passam a aceitar jargões como o 'livremente inspirado', na medida em que tomam a consciência que são hipertextos derivados de hipotextos preexistentes. A adaptação não cabe mais somente na relação entre literatura e roteiro, este agora encontra pares com a música, como em O Abismo Prateado (2011) ${ }^{1}$, de Karim Aïnouz; com as artes plásticas, como em Com amor, Van Gogh (Loving Vicent, 2017), de Dorota Kobiela e Hugh Welchman; e com as artes cênicas, como em Chi-raq (2015)², de Spike Lee, além do próprio Moonlight, a ser analisado logo adiante.

Antes, porém, torna-se necessário mais alguns questionamentos que justifiquem o embasamento teórico proposto por este estudo. Em Teoria e prática da adaptação: Da fidelidade à intertextualidade, Stam (2006, p. 35) até tenta propor um "modelo prático/ analítico” livre para análise do intertexto cinematográfico. Mas ao final da sua investigação, ele reconhece a amplitude desta temática, seja pelo vórtice infinito de reciclagem, transformação e transmutação, promovido por esse intertexto, seja pelo grande cumulativo que hipotextos anteriores a um filme adaptado podem sobrepor, sem um ponto claro de origem, diante de um desenvolvimento científico.

O próprio Stam (2017) reconhece que muito ainda há de ser feito, criado e revisado, sobretudo, diante da sua própria teoria. Acredita-se aqui que esta revisão deva incidir não somente sobre o binômio crítico-historiográfico supracitado, já muito bem estruturado pela teoria do audiovisual contemporânea, mas também sobre o estudo da realização cinematográfica em si. Quais seriam as etapas da transposição e adaptação de discurso entre determinada obra de arte e um roteiro cinematográfico? Seria este roteiro o estágio final deste processo? Visto que, em termos didáticos, nem a teoria, nem mesmo os manuais de roteiro, acham uma resposta assertiva para esta questão (REINIGER NETO, 2019), este artigo, movido pelo ímpeto pós-estruturalista da liberdade científica, vai atrás de áreas não tão comuns para responder essas perguntas.

É no encontro entre a semiótica e a leitura de distintas formas de arte que se pode pontuar um viés para a compreensão da criação cinematográfica, bem como o seu status no

1 Adaptado da música Olhos Nos Olhos (1976), de Chico Buarque.

2 Adaptado da peça teatral Lisístrata ou A Greve do Sexo (411 a. C.), de Aristófanes. 
que tange o processo de adaptação, agora não mais necessariamente literário, mas, sim, tão intertextual e convergente quanto o audiovisual. Cecilia Almeida Salles desenvolve este conceito ao chamá-lo de crítica genética, sobretudo, em seu artigo Diálogos entre pesquisadores de crítica genética: Brasil e França, na coletânea Processo de criação interartes: Cinema, teatro e edições eletrônicas (2004). Ela aponta os vestígios dessa metodologia já nos estudos literários da França, na década de 1960, e no intercâmbio que esses traçaram com o Brasil, ainda que não fossem denominados dessa maneira. Trata-se de um processo interdisciplinar, o qual desde seu início começou com um "acolhimento acadêmico; pessoas que tinham objetos de pesquisa e interesses em comum [...], um campo sempre em estado de expansão sob diferentes pontos de vista” (SALLES, 2004, p. 7). Nesta inter-relação acadêmica, de diferentes tipos de pesquisa, os manuscritos de distintos autores tornaram-se objeto de estudo. Um caminho para o encontro e compreensão dos principais clássicos da literatura, como os de Gustave Flaubert.

Foi na turbulência de 1968 que pesquisadores da França instigaram o mundo a enxergar esses documentos com algo advindo das mãos de um escritor, e não de um autor: um conceito de criação através da materialidade de uma escritura. Salles, no Programa de PósGraduação em Comunicação da Pontifícia Universidade Católica de São Paulo, expandiuos para outras áreas, embasando-os com os documentos do processo criativo, aquilo que não só os manuscritos, mas também outros registros, representam como “índices de um pensamento” (SALLES, 2004, p. 9). Caberia assim, ao seu trabalho, o desafio de construir um pensamento crítico capaz de atravessar as fronteiras dos gêneros e das artes. Com isso, além da literatura, o teatro e o cinema também passam a fazer interseções não só em seus estudos, como também nas obras de outros autores que encontram em seus pensamentos, um senso comum $^{3}$. Muitos, porém, relutaram em aceitar os documentos de um processo criativo como objeto, ou embasamento, de um estudo: fosse pelo desafio de romper com o senso comum das humanidades ao preterir o pensamento em detrimento da prática; fosse pela insegurança em lidar com outras formas de informações, as quais não fossem escritas. Nas artes cênicas, por exemplo, "são muitos os testemunhos do evento teatral, devido suas propriedades híbridas e complexas [...], mas apesar de tudo isso ser de suma importância no processo criativo, sua análise parece ainda não fazer parte do know how crítico” (GRÉSILLON; THOMASSEAU apud. SALLES, 2004, p. 8).

Nesta busca, o cinema, em especial, é investigado dentro do viés das etapas da sua produção. Processo de criação interartes: Cinema, teatro e edições eletrônicas, e até outras obras de Salles (2010), pontuam os seus documentos de criação. Storyboards e seus prédesenhos, além das anotações dos roteiristas, de início, até atendem a metodologia indicada, mas, pode-se perceber ao longo desta coletânea indícios de que a História desvirtue os reais objetivos dessas informações. Todos sabemos da relevância de obras como as de Serguei

3 Em Processos de criação interartes, mesmo Salles não sendo uma das organizadoras, seu capítulo supracitado é de extrema relevância por justamente apresentar e pontuar os principais pensamentos mundiais da crítica genética que foram traduzidos na edição deste livro. 
Eisenstein, como O encouraçado Potemkin (Броненосец Потёмкин, 1925), mas Ada Ackerman em Os desenhos preparatórios de Ivan, o Terrível [Иван Грозный,1944] (2004), ao adotar os pré-desenhos deste filme como método para a sua análise fílmica, dá a mais valia para o que já é senso comum na teoria do audiovisual, como a montagem soviética e o contexto sócio-político das suas narrativas, quando, com estas informações, poderia atentar para quais seriam as estratégias de produção adotadas na década de 1920. Qual seria, por exemplo, a interferência do poder estatal em algum direcionamento na construção do conteúdo nesta etapa de produção?

Ainda na tentativa do entrelace da crítica genética com o cinema, algo semelhante ocorre com Morgan Lefevure, no capítulo O storyboard: Uma ferramenta a serviço da criação cinematográfica. O exemplo de Quando desceram as trevas [Ministry of Fear, 1944], de Fritz Lang (2004). Os desenhos de Lang são adotados não para indicar traços da sua estética, ou do seu processo de criação, diante das adversidades tecnológicas que o cinema enfrentou na década de 1940. Ao longo do seu texto, Lefevure também adota o senso comum, enxerga esse diretor somente sob a óptica histórica, como um representante do expressionismo alemão, o que já é bem estruturado desde o final da década de 1920 nas críticas sobre as suas obras, como Metropolis (1927). Mas afinal, qual seria a via abordada por Processo de criação interartes capaz de ver, na crítica genética, uma alternativa para investigar a prática da adaptação de forma efetiva? Quem entenderia este processamento de forma convergente, tal qual o próprio cinema se comporta nas suas relações com outras mídias (JENKINS, 2006)?

Embora Salles (2010) possa ser considerada um referencial nesta metodologia, seus estudos não traçam a abordagem que Grésillon e Thomasseau executam, ao enveredarem pela investigação da criação teatral. Em Cenas de gêneses teatrais (2004), ambos os autores conseguem estabelecer indícios dos fatores buscados por este estudo. O teatro, tal qual o cinema, é uma obra mútua, composta pelo seu texto impresso e sua representação. As diferenças que podem existir entre os seus discursos são resultantes do processamento das suas respectivas criações, tornando-as não obras fechadas, após encenadas, mas, sim, obras abertas e concomitantes, passivas de leituras e construções de distintos estudos, críticas e pontos de vista. Os quais cabem à ciência a compreensão, bem como sua relevância na ode sociocultural.

É neste ponto que Moonlight é retomado, a fim de mostrar que seu roteiro e suas cenas (2016) não negam a sua gênese teatral (2003). Pelo contrário, constroem uma constância de relações e interações dialéticas, as quais ainda abrem as portas para que outras obras de arte sejam acrescentadas nas construções desta somatória de discursos. Tudo sem nulidade, sempre levando em conta as propriedades de cada um desses elementos em particular. A relação entre teatro e cinema, dentro do potencial convergente da adaptação, atenta que essa

(...) escritura do texto tem a cena como o seu horizonte de expectativa, que funciona como uma imagem mental secreta a ser alcançada; paralelamente ao 
texto impresso, a experiência concreta da encenação pode levar a reescrituras do texto e, até mesmo como se observa, sobretudo [...], à fixação definitiva da própria matéria textual (GRÉSILLON; THOMASSEAU, 2004, p. 117).

Não obstante, os tratamentos dos roteiros surgem, sobretudo, no universo da adaptação cinematográfica. Há uma necessidade de se solidificar, e não necessariamente equiparar, o dialogismo desses discursos. Moonlight carrega um fato que embasa esta questão: McCraney, autor da versão teatral, também trabalhou nos tratamentos do texto fílmico, sem se prender ao materialismo da sua criação, pelo contrário, adequando seu discurso para o novo formato o qual sua obra iria aportar. O filme apresenta três momentos da vida de um garoto negro, sobrevivente do narcotráfico na periferia de Miami; desde sua infância, quando era conhecido como Little (Alex Hibbert); passando pela sua adolescência, com o nome de Chiron (Ashton Sanders); até chegar à fase adulta, com o codinome Black (Trevante Rhodes). Filho de Paula (Naomi Harris), viciada em crack, ele se descobre gay e acaba por contar com os conselhos de Juan (Mahershala Ali), traficante do seu bairro. Em Moonlight, somente pelo fato do seu protagonista estar aparentemente divido em três personagens distintas, já temos uma construção narrativa longe de uma formatação audiovisual clássica. Atentamos, ainda, que essa narrativa tem um precedente, um eu lírico preexistente, cujas rubricas teatrais agora têm de fato as dimensões do espaço e do tempo a serem preenchidas. Constrói-se, assim, uma narrativa de catarse, por vezes não-verbal, aonde o protagonista encontra as condições ideais para romper com os dogmas da sua ambivalência mímica, oriundas do seu regime social, que o imergia em uma identidade que não era sua. Nesse silêncio, visto como um certo distanciamento em relação ao seu texto de origem, que o filme Moonlight utilizase de recursos interdisciplinares em seu discurso para desconstruir suas personagens e desenvolver sua trama.

Exemplifica-se, assim, que a gênese textual e a gênese cênica evoluem com o tempo e, ao longo das suas produções, as interações sistemáticas entre esses discursos são numerosas e mutáveis, mas sempre tomam a mise-en-scène como via para atingirem os seus feitos. Quando essa definição é considerada como o conjunto de ações físicas dentro de determinada profundidade de campo (BORDWELL, 2008) é que ela se dispõe sustentada pelos pilares texto e cena, e permite o trânsito para a coleta de dados em sistemas semióticos distintos, como a escrita, o visual e o auditivo. Assim, não só o adaptado vem à tona, mas, também, os seus elementos congêneres, como a voz, o espaço, os adereços, a luz, os deslocamentos, o corpo e a cenografia. Desta forma, a análise genética pode ser transportada e adaptada, do teatro ao cinema, ao considerar que a verdade da cena não está no funcionamento autônomo destes mecanismos separados, mas no movimento que os une e os dá vida (GRÉSILLON; THOMASSEAU, 2004). Nesta convergência que se forma, o drama acaba por se tornar uma essência que a narrativa constrói e quer contar, mas, nem sempre desmistificar.

Ainda sobre transposição do teatro ao cinema na crítica genética e como essa manobra pode auxiliar a compreensão da adaptação do texto fílmico diante da convergência 
que o sustenta na contemporaneidade, apontam-se outros fatores imprescindíveis para que se possa seguir com a análise fílmica proposta. A redação dos tratamentos do roteiro marca o momento em que o pensamento criativo se projeta diretamente sobre o horizonte cênico. A reunião dessas informações atua não só como o testemunho genético de uma obra, mas também atenta para o fato de que esse texto, ao ser encenado, liberta-se da sua base, não a requerendo enquanto índice, mas sim construindo uma camada de

(...) signos e sensações [...], um tipo de percepção geral de estratégias, que incluem [...] gestos, tons, distâncias, substâncias, luzes, que permeiam o texto com a plenitude de uma linguagem a qual aponta para o mundo exterior (BARTHES apud. GRÉSILLON; THOMASSEAU, 2004, p. 120).

É na quebra dessa fidelidade, que não segue a cronologia de uma criação, que a crítica genética coleta as pistas deixadas pelos hipotextos da cena, não enquanto perda, mas, sim, como discurso e ferramenta da análise fílmica. O autor desta, quando percebe que pode deambular entre os papéis de leitor e espectador, ao considerar a encenação não enquanto fim, mas como etapa de uma obra, pode buscar outras fontes de informações para os seus estudos e ver o adaptar não como sinônimo de redução, mas, sim, de interação com outras formas de arte.

O texto de um roteiro não é só uma obra em si, mas também um agente de ligação entre a concepção e a experimentação cinematográfica. Na gênese cênica, sua forma verbal se transforma em corpo, gesto, espaço e movimento. O cinema, neste estudo, é considerado como um processo. Seu conteúdo audiovisual é uma, mas não a única possibilidade de leitura dos seus parâmetros textuais. Cada interpretação do seu discurso sempre renovará o seu potencial. Sua encenação pode estabelecer conexões que nos convocam aos mais distintos pontos de vista nas suas análises.

Ao fim, no intuito de ilustrar o recorte teórico até aqui construído, pontuam-se mais dois momentos da narrativa de Moonlight que convergem texto e encenação ao longo do seu processo criativo. Convergem, sobretudo, no âmbito da crítica genética, na medida em que o dialogismo do seu discurso textual garante a manutenção da sua mise-en-scène, independente do locus da sua encenação. Não há como negar o passado teatral que Tarell Alvin McCraney levou em sua coautoria no roteiro com Barry Jenkins e, no que tange à essência convergente constatada no âmbito da adaptação na contemporaneidade, este valor pode ser considerado como um catalisador interartístico, responsável por enriquecer a construção intersemiótica do seu discurso. Moonlight preza pela inadequação das identidades dos seus sujeitos nos espaços em que eles vivem. Ao longo de toda a trama, os diálogos perdem força ou ganham outra forma para que, nas relações interpessoais, simulacros e simulações (BAUDRILLARD, 1991) de um outro eu surjam na narrativa. O que o teatro processa com um recorte de luz na criação dessa relação, a direção de fotografia de Moonlight, realizada por James Laxton, recorre ao uso de lentes grande- 
angulares (RODRIGUES, 2002) em todo o seu discurso, para o desfoque do seu entorno e a ênfase em seus sujeitos.

Figura 1 - O uso de lente grande-angular na direção de fotografia de Moonlight.

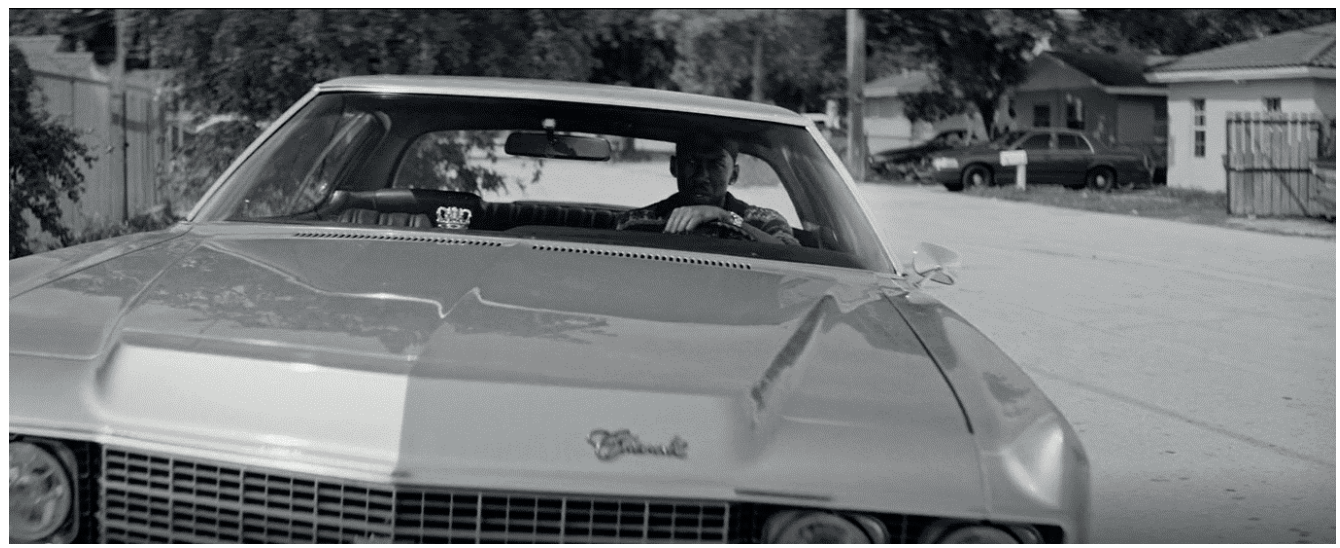

Fonte: IMDB - Internet Movie Database (2016).

Nessa modelagem do espaço diegético, o caráter performático da narrativa, descrito ao longo de todo o roteiro, parece encontrar as condições ideais para a sua concretização. Na sequência 31, do seu último tratamento, encontra-se a descrição da seguinte situação: "Paula e Little se encaram. Little parado sob os pés da sua mãe. Nós os observamos no decorrer de algo, ao final de algo” (JENKINS, 2016, p. 28 - Tradução nossa). Pelos parâmetros propostos por Comparato (2000) ${ }^{4}$ e outros autores de manuais de roteiro, esta seria uma sequência próxima de dez segundos de duração, na medida em que ocupa 1/6 da sua página. Podese dizer que a mesma ainda tem alguma relação com a obra de Caravaggio, Madonna e a criança com Santa Ana (Madonna dei palafrenieri, 1605), por fazer alusão à mãe que carrega o filho sob os seus pés.

Mas, como indício de que a crítica genética enxerga o cinema como uma obra inacabada, ou que agrega adequações ao longo do seu processo de criação, percebe-se que o construto do discurso de Moonlight não resultou nesta informação. Esta cena, no filme, tem não só uma duração maior, como também uma outra decupagem, um outro eixo de disposição dos seus atores. A trilha sonora extra-diegética - a qual conta com a composição de The Spot, do jovem pianista Nicholas Britell (2016) - também é responsável por induzir esta leitura. A gênese criativa deste ato veio de um texto, mas a forma como esse está disposto em seu roteiro enfatiza a conduta de Barry Jenkins em sua produção. Não há nem mesmo como nos aproximarmos de um melodrama clássico (ALTMAN, 2000), pois a música suprime o diálogo das personagens. Paula e Little se encaram, em diâmetros opostos. O olhar do

4 O qual considera um minuto de filme, o equivalente a uma página de roteiro. 
garoto é passivo. Só lhe resta ser conivente com esta situação. A repreensão da sua mãe, desnecessária. Suprimida pela trilha, o status da sua atuação já passa a mensagem desejada.

Figura 2 - Madonna e a criança com Santa Ana (1605), de Caravaggio, e a mise-en-scène de Moonlight
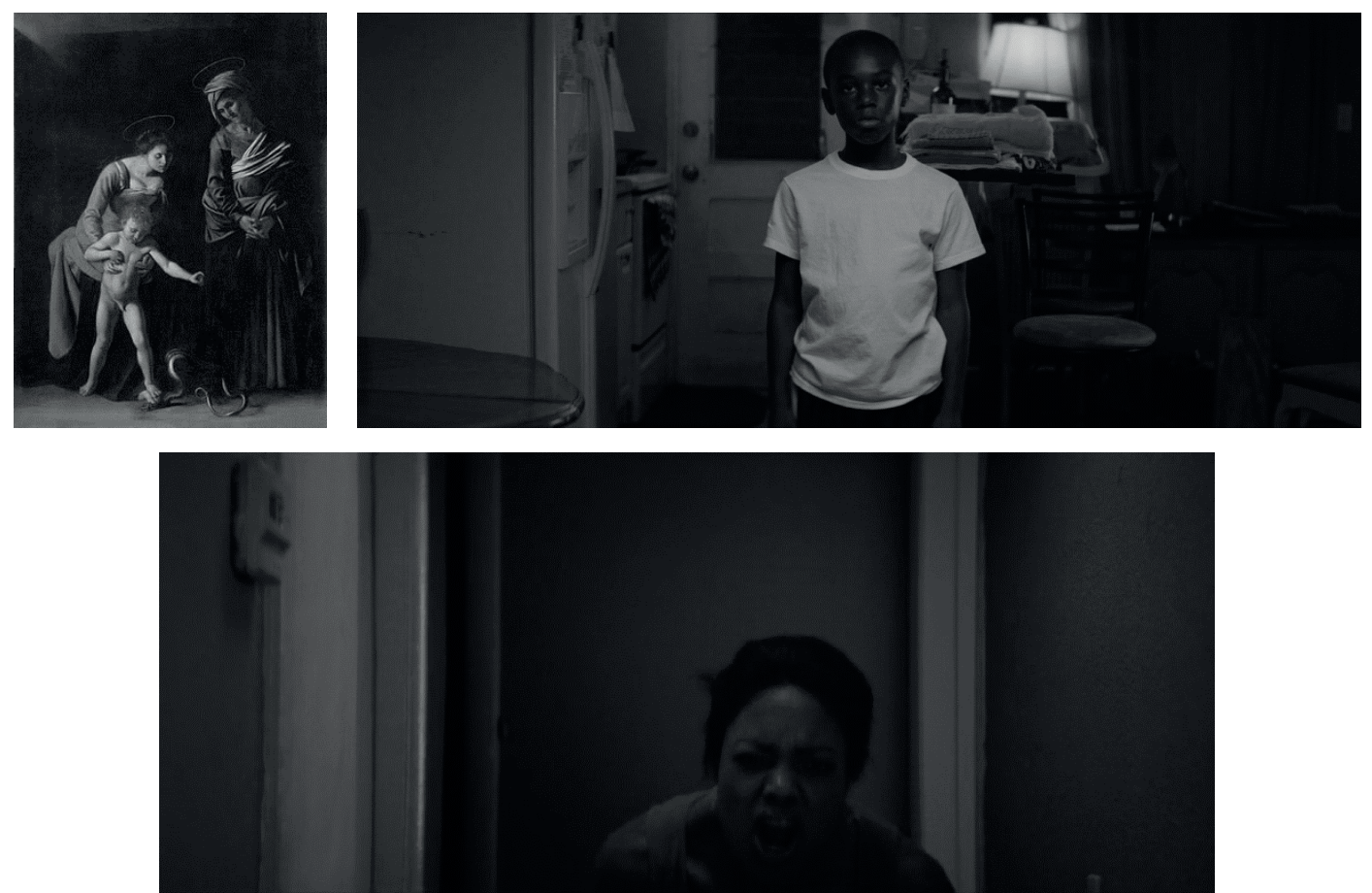

Fontes: Galleria Borghese (1605) e IMDB - Internet Movie Database (2016).

No segundo momento elencado para esta análise, percebe-se que anos depois, na sequência 83 do roteiro, Little, o qual então atende pelo codinome Black, decide reencontrar seu amigo Kevin (André Holland), com o qual tinha tido sua primeira experiência homossexual, quando criança. Fato não levado adiante, pois, devido as políticas de identidade no habitat onde eles estavam inseridos, diante do narcotráfico, o simulacro (BAUDRILLARD, 1991) heteronormativo era uma estratégia de sobrevivência. Kevin, ainda na sua adolescência, foi preso. Em uma visita íntima, engravidou Samantha (Hevelin Morcion). Seu filho, Kevin Jr., agora precisaria de um pai que o sustentasse. Ele então, percebeu que era necessário se recompor, retomar a sua vida, ainda que em liberdade condicional. Black enveredou pelo narcotráfico, passou a cuidar de todos os bens deixados pelo seu mentor, Juan. Agora, de porte atlético, armas, piercings e carro do ano, faz uso de todas essas alegorias para impor o medo. Quando, na verdade, este medo viria a ser um gatilho para expor os seus reais sentimentos pelo seu velho amigo. Black e Kevin encontram-se no restaurante onde este 
trabalha. Com o que ele aprendeu no cárcere, acabou tomando gosto pela culinária, o que o levou a cozinhar, com afeto, para a sua inesperada visita.

Kevin o serve: arroz, feijão e peixe, regado à vinho. Os dois conversam como que em um processo de reconhecimento de território. Aos poucos, cada um abre mão da alegoria a qual utilizava para a manutenção do status e Black assume que, salvo o seu trabalho, nada mudou. Ainda está solteiro. Eventualmente, visita a sua mãe na clínica de reabilitação em Atlanta. No roteiro de Jenkins e McCraney, ao final desta sequência, há mais um indício do quão a crítica genética pode ser relevante para o estudo da adaptação cinematográfica contemporânea. A trilha sonora, a qual costumeiramente é marcada somente na pósprodução de um filme (RODRIGUES, 2002), nesta ocasião, tem sua presença já demarcada em seu roteiro, sua gênese criativa. Assim, a música Hello Stranger (1963), de Barbara Lewis, assume o papel de instância narrativa (AUMONT, 2012), torna-se não um artefato melodramático, um climatizador da diegese (TRAGTENBERG, 1999), mas o diálogo entre as personagens, adaptado a cada gesto, a cada olhar, conforme informam as estrofes abaixo

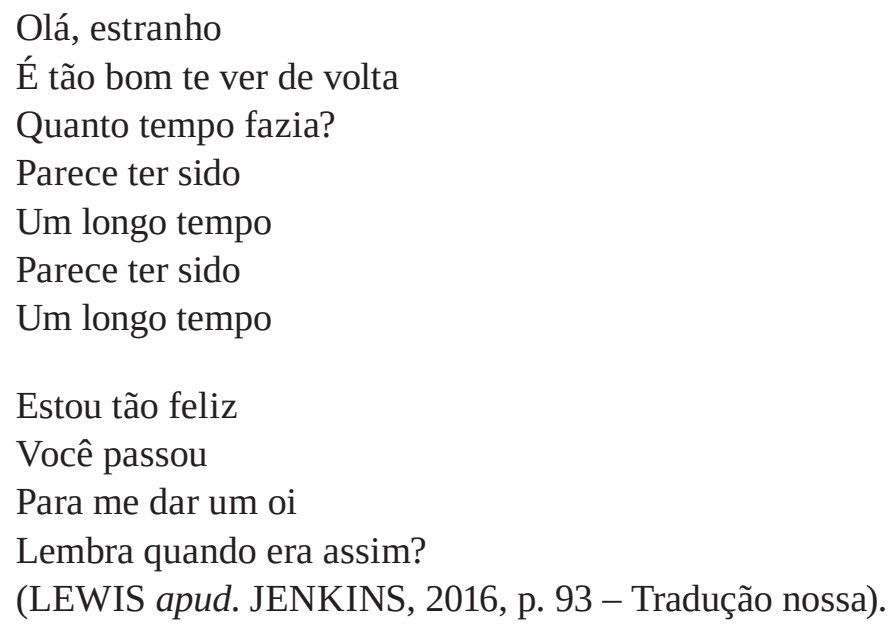

Sequências depois, Black assume que Kevin foi o seu único homem. Que desde a primeira relação entre eles, na areia da praia, sob a luz do luar, nunca mais ninguém havia o tocado. Os amigos não transam novamente e a narrativa de Barry Jenkins chega ao seu fim. Mais do que um formato clássico, uma moral da história, ou um final feliz, sua trama busca um esclarecimento, uma ressignificação para a política de identidade do seu protagonista. Um jovem incrédulo do seu inconsciente e alvejado pela minoria da qual fazia parte, o qual buscou unicamente alguma alternativa para sobreviver.

Apesar dos novos tempos, pouco se esperava que uma produção tão experimental, ou até mesmo subversiva em sua estética e linguagem, ganhasse os Oscars de Melhor Filme, Ator Coadjuvante (Mahershala Ali) e Roteiro Adaptado. Neste estudo, não se buscou uma 
investigação ampla e detalhista de todo o seu conteúdo, mas, sim, o objetivo de pontuar que a metodologia de pesquisa para a teoria do audiovisual contemporânea, quando se porta de modo convergente, tal qual o seu próprio cerne, só tende a enriquecer. A crítica genética de Salles (2004), ainda que imprecisa para com o cinema, é aberta ao afeto e não à crítica científica. Não há o status quo de somente um dos polos do discurso adaptado, mas, sim, o resgate, ou o diálogo, com a intertextualidade de Robert Stam e a constância dialógica de Mikhail Bakhtin.

A crítica genética tem dado ênfase à questão do inacabado. O processo de criação é um work in progress o qual permite infinitas incorporações, representações e leituras de um texto. Um processo aberto que, se assim considerado, poderá trazer o roteiro, ao cinema e ao próprio audiovisual, reflexões contemporâneas para sempre renovarmos o domínio das suas estéticas e das suas epistemologias.

\section{Referências}

ACKERMAN, A. Os desenhos preparatórios de Ivan, o Terrível, que tipo de ferramenta genética? A análise aplicada aos filmes. In: PASSOS, M. H. P.; SOARES, N. G.; ROMANELLI, S., et al. Processos de criação interartes: cinema, teatro e edições eletrônicas. Vinhedo: Ed. Novo Horizonte, 2010. p. 61-87.

ALTMAN, R. Los generos cinematograficos. Barcelona: Ed. Paidós, 2000. 332 p.

AUMONT, J. A estética do filme. Campinas: Ed. Papirus, 2012. 304 p.

BAUDRILLARD, J. Simulacros e simulação. Lisboa: Ed. Relógio D’Agua, 1991. 208 p.

BORDWELL, D. Figuras traçadas na luz: a encenação no cinema. Campinas: Ed. Papirus, 2008. 352 p.

BRITELL, N. The Spot. Moonlight Original Sound Track (OST). Spotify. Disponível em: https://open. spotify.com/track/4gxVrGdFlhWAdl6PVC1yBY. Acesso em: 20 out. 2019.

CARAVAGGIO. Madonna dei palafrenieri. 1605. 1 tela. Galleria Borghesi.

CHI-RAQ. IMDB - Internet Movie Database. Disponível em: https://www.imdb.com/title/tt4594834. Acesso em: 20 out. 2019.

COM AMOR, VAN GOGH. IMDB - Internet Movie Database. Disponível em: https://www.imdb.com/ title/tt3262342. Acesso em: 20 out. 2019.

COMPARATO, D. Da criação ao roteiro. 5a. ed. Rio de Janeiro: Ed. Rocco, 2000. 496 p.

GRÉSILLON; THOMASSEAU. Cenas de gêneses teatrais. In: PASSOS, M. H. P.; SOARES, N. G.; ROMANELLI, S., et al. Processos de criação interartes: cinema, teatro e edições eletrônicas. Vinhedo: Ed. Novo Horizonte, 2010. p. 117-136.

IVAN, O TERRÍVEL. IMDB - Internet Movie Database. Disponível em: https://www.imdb.com/title/ tt0037824. Acesso em: 20 out. 2019.

JENKINS, B. Moonlight. Based on "In Moonlight Black Boys Like Blue” By Tarell Alvin McCraney. 2016. DailyScript. Disponível em: https://www.dailyscript.com/scripts/MOONLIGHT.pdf. Acesso em: 20 out. 2019.

JENKINS, H. Cultura da convergência. Tradução Susana Alexandria. 2a. ed. São Paulo: Ed. Aleph, 2006. 432p. 
LEVEFURE, M. O storyboard: Uma ferramenta a serviço da criação cinematográfica. O exemplo de Ministry of fear, de Fritz Lang. In: PASSOS, M. H. P.; SOARES, N. G.; ROMANELLI, S., et al. Processos de criação interartes: cinema, teatro e edições eletrônicas. Vinhedo: Ed. Novo Horizonte, 2010. p. 89-116.

LEWIS, B. Hello Stranger. Moonlight Original Sound Track (OST). Spotify. Disponível em: https://open. spotify.com/track/55n3Aq5p4uLHHhZ1u0R3BW. Acesso em: 20 out. 2019.

METROPOLIS. IMDB - Internet Movie Database. Disponível em: https://www.imdb.com/title/tt0017136. Acesso em: 18 out. 2019.

MOONLIGHT. IMDB - Internet Movie Database. Disponível em: https://www.imdb.com/title/tt4975722. Acesso em: 20 out. 2019.

O ABISMO PRATEADO. IMDB - Internet Movie Database. Disponível em: https://www.imdb.com/title/ tt1725057. Acesso em: 20 out. 2019.

O ENCOURAÇADO POTEMKIN. IMDB - Internet Movie Database. Disponível em: https://www.imdb. com/title/tt0015648. Acesso em: 20 out. 2019.

PASSOS, M. H. P.; SOARES, N. G.; ROMANELLI, S., et al. Processos de criação interartes: cinema, teatro e edições eletrônicas. Vinhedo: Ed. Novo Horizonte, 2010. 224 p.

QUANDO DESCERAM AS TREVAS. IMDB - Internet Movie Database. Disponível em: https://www. imdb.com/title/tt0037075. Acesso em: 20 out. 2019.

REINIGER NETO, R. G. Entre recortes, intertextualidades e ambivalências: a adaptação do livro Memória Impura para um roteiro de filme de longa-metragem. 2019. 360 p. Tese (Doutorado em Ciências da Comunicação. Programa de Pós-Graduação em Comunicação, Universidade Anhembi Morumbi. 2019.

RODRIGUES, C. O cinema e a produção. Rio de Janeiro: Ed. FAPERJ / DP\&A, 2002. 264 p.

SALLES, C. A. Arquivos de criação: arte e curadoria. Vinhedo: Ed. Novo Horizonte, 2010. 236p.

SALLES, C. A. Diálogos entre pesquisadores de crítica genética: Brasil e França. In: PASSOS, M. H. P.; SOARES, N. G.; ROMANELli, S., et al. Processos de criação interartes: cinema, teatro e edições eletrônicas. Vinhedo: Ed. Novo Horizonte, 2010. p. 7-16.

STAM, R. A literatura através do cinema: realismo, magia e a arte da adaptação. Belo Horizonte: Ed. UFMG, 2008. 511p.

STAM, R. Teoria e prática da adaptação: Da fidelidade à intertextualidade. Revista Ilha do Desterro. Universidade Federal de Santa Catarina. UFSC. Florianópolis, n. 51, p. 19-53, jul./dez. 2006. Disponível em: https://periodicos.ufsc.br/index.php/desterro/article/view/2175-8026.2006n51p19/9004. Acesso em: 20 out. 2019.

TRAGTENBERG, L. Música de cena: dramaturgia sonora. São Paulo: Ed. Perspectiva / FAPESP, 1999. 176p. VADICO, L.; REINIGER NETO, R. G. Robert Stam - Cinema, Literatura e a trajetória de uma metodologia de pesquisa. Intercom: Revista Brasileira de Ciências da Comunicação. São Paulo, v. 40, n. 2, p. 203-212, maio/ago. 2017. Disponível em: http://portcom.intercom.org.br/revistas/index.php/revistaintercom/article/ view/2703/2069. Acesso em: 20 out. 2019.

\section{Roberto Gustavo Reiniger Neto}

Formado pela Universidade Federal de São Carlos. Bacharel, Mestre e Doutor em Comunicação Audiovisual. É membro da AsAECA - Asociación Argentina de Estudios Sobre Cine y Audiovisual e da ABRA - Associação Brasileira de Autores Roteiristas. Autor dos livros "Almodovarianas: A função narrativa das encenações 
dos números musicais na filmografia de Pedro Almodóvar" (2018), "Entre recortes, intertextualidades e ambivalências" (2019) e "Memórias de um filme que vocês não vão ver" (2020). Aualmente, dedica-se à publicação de sua próxima obra "Cinema: Interface, Navegação e Interação”, além de trabalhar em projetos de publicidade, televisão e marketing digital. E-mail: roberto.reiniger@gmail.com.

Recebido em: 13.11.2019 Aprovado em: 26.08.2020 